\title{
Improvement in Device Performance and Reliability of Organic Light-Emitting Diodes through Deposition Rate Control
}

\author{
Shun-Wei Liu, ${ }^{1}$ Chih-Chien Lee, ${ }^{2}$ Yu-Ting Chung, ${ }^{2}$ Jiun-Haw Lee, ${ }^{3}$ \\ Chin-Ti Chen, ${ }^{4}$ and Juen-Kai Wang ${ }^{5,6}$ \\ ${ }^{1}$ Department of Electronic Engineering, Ming Chi University of Technology, New Taipei City 24301, Taiwan \\ ${ }^{2}$ Department of Electronic Engineering, National Taiwan University of Science and Technology, Taipei 106, Taiwan \\ ${ }^{3}$ Graduate Institute of Photonics and Optoelectronics and Department of Electrical Engineering, \\ National Taiwan University, Taipei 106, Taiwan \\ ${ }^{4}$ Institute of Chemistry, Academia Sinica, Taipei 11529, Taiwan \\ ${ }^{5}$ Center for Condensed Matter Sciences, National Taiwan University, Taipei 106, Taiwan \\ ${ }^{6}$ Institute of Atomic and Molecular Sciences, Academia Sinica, Taipei 106, Taiwan
}

Correspondence should be addressed to Jiun-Haw Lee; jiunhawlee@ntu.edu.tw and Chin-Ti Chen; cchen@chem.sinica.edu.tw

Received 25 February 2014; Revised 9 April 2014; Accepted 10 April 2014; Published 27 April 2014

Academic Editor: K. R. Justin Thomas

Copyright (C) 2014 Shun-Wei Liu et al. This is an open access article distributed under the Creative Commons Attribution License, which permits unrestricted use, distribution, and reproduction in any medium, provided the original work is properly cited.

\begin{abstract}
We demonstrated a fabrication technique to reduce the driving voltage, increase the current efficiency, and extend the operating lifetime of an organic light-emitting diode (OLED) by simply controlling the deposition rate of bis(10-hydroxybenzo[h]qinolinato) beryllium $\left(\mathrm{Bebq}_{2}\right)$ used as the emitting layer and the electron-transport layer. In our optimized device, $55 \mathrm{~nm}$ of $\mathrm{Bebq}_{2}$ was first deposited at a faster deposition rate of $1.3 \mathrm{~nm} / \mathrm{s}$, followed by the deposition of a thin $\mathrm{Bebq}_{2}(5 \mathrm{~nm})$ layer at a slower rate of $0.03 \mathrm{~nm} / \mathrm{s}$. The $\mathrm{Bebq}_{2}$ layer with the faster deposition rate exhibited higher photoluminescence efficiency and was suitable for use in light emission. The thin $\mathrm{Bebq}_{2}$ layer with the slower deposition rate was used to modify the interface between the Bebq $\mathrm{q}_{2}$ and cathode and hence improve the injection efficiency and lower the driving voltage. The operating lifetime of such a two-step deposition OLED was 1.92 and 4.6 times longer than that of devices with a single deposition rate, that is, 1.3 and $0.03 \mathrm{~nm} / \mathrm{s}$ cases, respectively.
\end{abstract}

\section{Introduction}

Molecular packing plays an important role in the function of organic electronics and optoelectronic devices [1-5]. For organic thin-film transistor (OTFT) applications, appropriate packing produces higher field-effect mobility resulting in increased electrical current [1]. Molecular packing of organic materials for OTFT (such as pentacene) can be adjusted by introducing the substituent to the molecules, surface treatment (e.g., octadecyltrichlorosilane), or insertion of self-assembled monolayer $[6,7]$. For polymer solar cell application, molecular packing can be controlled by fabrication techniques such as thermal annealing or solvent annealing. Better molecular packing of donor material (e.g., poly(3-hexylthiophene)) not only improved hole mobility and charge balance but also increased absorption $[8,9]$. For the small-molecular organic solar cell, molecular packing plays an important role in determining the open circuit voltage $\left(V_{\mathrm{OC}}\right)$. For organic materials with higher crystallinity, it resulted in higher saturation dark current, and in turn reduced the $V_{\mathrm{OC}}$ and hence power conversion efficiency, which can be engineered by inserting an interfacial layer or varying evaporation rate $[10,11]$. For the organic lightemitting diode (OLED) application, we demonstrated in our previous study that molecular packing of a planar molecule, bis(10-hydroxybenzo[h]qinolinato) beryllium $\left(\mathrm{Bebq}_{2}\right)$, can be controlled via the deposition rate during vacuum sublimation [12-14]. Atomic force microscopy (AFM) measurements confirmed that a slower deposition rate (i.e., $0.03 \mathrm{~nm} / \mathrm{s}$ ) resulted in better molecular packing. When slower-deposition rate $\mathrm{Bebq}_{2}$ was used as the emitting layer (EML) and the electron-transporting layer (ETL) material 
in our OLED, such an ordered molecular packing improved electron mobility and reduced driving voltage. On the other hand, the ordered $\mathrm{Bebq}_{2}$ resulted in a photoluminescence (PL) quenching and a lower current efficiency (in terms of $\mathrm{cd} / \mathrm{A}$ ), so there appeared to be a tradeoff between the electrical and optical properties.

The deposition rate of organic materials was generally controlled at $\sim 0.1 \mathrm{~nm} / \mathrm{s}$, with some fluctuations (e.g., $0.08-0.12 \mathrm{~nm} / \mathrm{s}$ ). An ultralow deposition rate (e.g., less than $0.01 \mathrm{~nm} / \mathrm{s}$ ) meant that device fabrication took a long time and was impractical from a manufacturing point of view. On the other hand, at ultrahigh deposition rates (e.g., higher than $10 \mathrm{~nm} / \mathrm{s}$ ) precise control over the thickness of the organic layer became problematic. This paper therefore looks at deposition rates between 0.03 and $1.3 \mathrm{~nm} / \mathrm{s}$ due to practical considerations such as takt time and precise thickness control. During the evaporation process, temperature was carefully adjusted to achieve constant deposition rates of 0.03 , 0.3 , and $1.3 \mathrm{~nm} / \mathrm{s}$ with fluctuations of $0.02-0.04,0.27-0.33$, and $1.1-1.4 \mathrm{~nm} / \mathrm{s}$, respectively. The separation of deposition rates was sufficient to avoid any possible overlap due to fluctuation in deposition rate.

In this report, we made use of a two-step evaporation technique for depositing $\mathrm{Bebq}_{2}$ at high and low rates sequentially. First, $55 \mathrm{~nm}$ of $\mathrm{Bebq}_{2}$ was deposited at a fast rate $(1.3 \mathrm{~nm} / \mathrm{s})$ to form the EML (and ETL as well) alleviating the PL quenching at the recombination zone near the HTL/EML interface. This was followed by the deposition of a $\mathrm{Bebq}_{2}$ thin layer $(5 \mathrm{~nm})$ at a slow rate $(0.03 \mathrm{~nm} / \mathrm{s})$ to modify the interface between the ETL and the cathode for efficient electron injection, which was deduced from electron-only device and AFM measurement. Although $\mathrm{Bebq}_{2}$ with slower deposition rate exhibited the lowest PL efficiency, it did not affect the device performances because it was far away from the recombination zone.

\section{Experiment}

To study the effects of the deposition rate on the device performance and lifetime of the electroluminescence (EL) device, five different device structures were fabricated, as summarized in Table 1. The authors selected ITO/NPB $(60 \mathrm{~nm}) / \mathrm{Bebq}_{2},(55 \mathrm{~nm}) / \mathrm{Bebq}_{2},(5 \mathrm{~nm}) / \mathrm{LiF}$, and $(1 \mathrm{~nm}) / \mathrm{Al}$ $(100 \mathrm{~nm})$ as the EL samples, in which the $5 \mathrm{~nm}$ thick Bebq layer was deposited at three different rates of $0.03 \mathrm{~nm} / \mathrm{s}$ (device A), $0.3 \mathrm{~nm} / \mathrm{s}$ (device B), and $1.3 \mathrm{~nm} / \mathrm{s}$ (device C). OLEDs with different single deposition rates $(0.3$ and $0.03 \mathrm{~nm} / \mathrm{s}$ ) were also fabricated and designated as devices $\mathrm{D}$ and $\mathrm{E}$, respectively. The fabrication process was similar to that outlined in our previous reports, except for the purification process of the organic materials [15]. For this experiment, the organic materials were purified three times by temperature-gradient sublimation. This change indeed resulted in significant changes to the lifetime performances compared to our previous studies [14]. Despite similar device configurations and aging conditions, the operating lifetimes observed in this project were approximately 10 times longer than those in our previous paper [14]. We
TABLE 1: (a) Five different device structures used to investigate the dependence of device performance on deposition rate of ultrathin ETL. Consider $(x, y)=(1.3,0.03),(1.3,0.3),(1.3,1.3),(0.3,0.3)$, and $(0.03,0.03)$ for devices A, B, C, D, and E, respectively. (b) Three different device structures used to investigate the electron injection characteristics on deposition rate of ultrathin ETL. Consider $z=$ $0.03,0.3$, and 1.3 for devices $F, G$, and $H$, respectively.

(a)

\begin{tabular}{l}
$\mathrm{LiF} / \mathrm{Al}, 1 / 100 \mathrm{~nm}$ \\
$\mathrm{Bebq}_{2}, 5 \mathrm{~nm}, y \mathrm{~nm} / \mathrm{s}$ \\
$\mathrm{Bebq}_{2}, 55 \mathrm{~nm}, x \mathrm{~nm} / \mathrm{s}$ \\
$\mathrm{NPB}, 60 \mathrm{~nm}$ \\
$\mathrm{ITO}, 80 \mathrm{~nm}$ \\
Glass \\
\hline
\end{tabular}

(b)

$\mathrm{Ca}, 150 \mathrm{~nm}$
$\mathrm{Bebq}_{2}, 5 \mathrm{~nm}, z \mathrm{~nm} / \mathrm{s}$
$\mathrm{Bebq}_{2}, 55 \mathrm{~nm}, 1.3 \mathrm{~nm} / \mathrm{s}$
$\mathrm{Ca}, 150 \mathrm{~nm}$
Glass

also measured the $J-V$ characteristics of the single carrier (electron) device to investigate the injection characteristics of the organic/electrode interface [16]. The device structures were $\mathrm{Ca}(150 \mathrm{~nm} ; 0.1 \mathrm{~nm} / \mathrm{s}) / \mathrm{Bebq}_{2},(55 \mathrm{~nm} ; 1.3 \mathrm{~nm} / \mathrm{s}) / \mathrm{Bebq}_{2}$, $(5 \mathrm{~nm} ; 0.03,0.3$ and $1.3 \mathrm{~nm} / \mathrm{s}) / \mathrm{Ca}$, and $(150 \mathrm{~nm} ; 0.1 \mathrm{~nm} / \mathrm{s})$ on glass substrate, designated as devices $F, G$, and $H$, respectively. For our fabrication, the ITO/glass substrate (sheet resistance $\sim 30 \Omega / \square$ ) was commercially obtained from the Merck Corporation, with the low energy method (AC2; Riken Keiki) yielding a work function of $4.8 \mathrm{eV}$ for the ITO. During the film deposition of the devices, the pressure of the chamber was maintained at below $4 \times 10^{-6}$ torr. The thickness of each organic layer was calibrated by a surface profiler (Dektak 150; Veeco) before device fabrication. The active area of the devices was $4 \mathrm{~mm}^{2}$ and the devices were completed with an encapsulation in a glove box $\left(\mathrm{O}_{2}\right.$ and $\mathrm{H}_{2} \mathrm{O}$ concentration below $0.1 \mathrm{ppm})$. A DC current/voltage source meter (2400; Keithley) was used to measure current density versus voltage characteristics, while the brightness was monitored with a spectrophotometer (PR650; Photo Research). The device lifetime was determined with a constant current density of $100 \mathrm{~mA} / \mathrm{cm}^{2}$ in a DC driving condition. For AFM measurement (noncontact mode; Park system XE-100), the Si wafer was sequentially sonicated in acetone, methanol, and deionized water, and etched in dilute $\mathrm{H}_{2} \mathrm{SO}_{4}$ solution. Immediately after cleaning, the substrates were transferred into an evaporation chamber for deposition of the organic thin film. The surface roughness of the cleaned Si wafer was $0.2 \mathrm{~nm}$.

\section{Results and Discussion}

3.1. Device Performances. Figure 1 shows the $J-V$ characteristics and EL efficiency of devices A-E. The only difference 
in the OLED fabrication process among devices $\mathrm{A}, \mathrm{B}$, and $\mathrm{C}$ was the deposition rate of the ultrathin $\mathrm{Bebq}_{2}$ at the $\mathrm{LiF} / \mathrm{Al}$ interface, with these being $0.03,0.3$, and $1.3 \mathrm{~nm} / \mathrm{s}$, respectively, while the deposition rate of the thick $\mathrm{Bebq}_{2}$ at the $\mathrm{HTL}$ interface was maintained at $1.3 \mathrm{~nm} / \mathrm{s}$. One should note that the current density decreased monotonically from 25.8 to $11 \mathrm{~mA} / \mathrm{cm}^{2}$ at $6 \mathrm{~V}$ when the deposition rate of the final $\mathrm{Bebq}_{2}$ layer was increased from 0.03 to $1.3 \mathrm{~nm} / \mathrm{s}$. When devices $\mathrm{C}$, $\mathrm{D}$, and $\mathrm{E}$ were compared with cases where the entire $\mathrm{Bebq}_{2}$ layer was deposited at a constant evaporation rate of 1.3, 0.3, and $0.03 \mathrm{~nm} / \mathrm{s}$, respectively, current density increased monotonically as the deposition rate decreased, because lower evaporation rates resulted in higher electron mobility [17]. By comparing the $J-V$ characteristics of devices $\mathrm{A}, \mathrm{B}$, and $\mathrm{C}$, we can see that the ultrathin $\mathrm{Bebq}_{2}$ film $(5 \mathrm{~nm})$ near the LiF/Al interface helped to reduce the driving voltage; that is, this thin layer may facilitate better electron injection from the cathode into the ETL and EML. To confirm this hypothesis, three electron-only devices with the device structure shown in Table 1 were fabricated. A thick $\mathrm{Bebq}_{2}(55 \mathrm{~nm} ; 1.3 \mathrm{~nm} / \mathrm{s})$ layer followed by a thin $\mathrm{Bebq}_{2}(5 \mathrm{~nm})$ layer deposited at rates of $0.03,0.3$, and $1.3 \mathrm{~nm} / \mathrm{s}$, respectively, was sandwiched between two Ca electrodes. Figure 2 shows the $J-V$ characteristics of the electron-only devices. As expected, the electron-only device with a thin $\mathrm{Bebq}_{2}(5 \mathrm{~nm})$ layer of the lowest deposition rate $(0.03 \mathrm{~nm} / \mathrm{s})$ exhibited the highest current density due to better electron injection capability, consistent with the device performances observed in Figure 1(a). By optimizing the carrier injection and carrier transport, one can theoretically obtain an OLED with the lowest driving voltage (device E). For the cases with a single deposition rate $(1.3,0.3$, and $0.03 \mathrm{~nm} / \mathrm{s}$, corresponding to devices $\mathrm{C}, \mathrm{D}$, and $\mathrm{E}$, resp.), one can note that the current efficiency decreased with the deposition rate, as shown in Figure 1(b), due to the decrease in PL efficiency with better molecular packing at a lower deposition rate [14]. By changing the deposition rate of the thin $(5 \mathrm{~nm}) \mathrm{Bebq}_{2}$ layer close to LiF/Al (devices A, B, and C), the current efficiency decreased monotonically from 7.5 to $5.4 \mathrm{~cd} / \mathrm{A}$ at $100 \mathrm{~mA} / \mathrm{cm}^{2}$ when the deposition rate of the final $\mathrm{Bebq}_{2}$ layer was increased from 0.03 to $1.3 \mathrm{~nm} / \mathrm{s}$. The change can be attributed to better electron injection at the cathode interface and hence better electron/hole balance [18-20]. By simply decreasing the evaporation rate at the ETL and LiF/Al interface, device performances were significantly improved with lower driving voltages and higher current efficiencies.

3.2. Accelerated Lifetime Test. To evaluate the effects of the $\mathrm{Bebq}_{2} /$ electrode on the device lifetime, the five types of $\mathrm{Bebq}_{2}$ based devices (A-E) were measured at a constant DC driven current density of $100 \mathrm{~mA} / \mathrm{cm}^{2}$. Figures 3(a) and 3(b) show the time dependent variations of the device luminance and driving voltage. The initial luminance was $7470,7300,5320$, 3360 , and $3220 \mathrm{~cd} / \mathrm{m}^{2}$ for devices $\mathrm{A}, \mathrm{B}, \mathrm{C}, \mathrm{D}$, and E, respectively. No detectable change in the EL spectra was observed for the five OLEDs during the accelerated lifetime test. This evidence suggested that there was no change in the chemical nature of these organic layers and no drastic alteration in the emission zone location during device operation; that is,

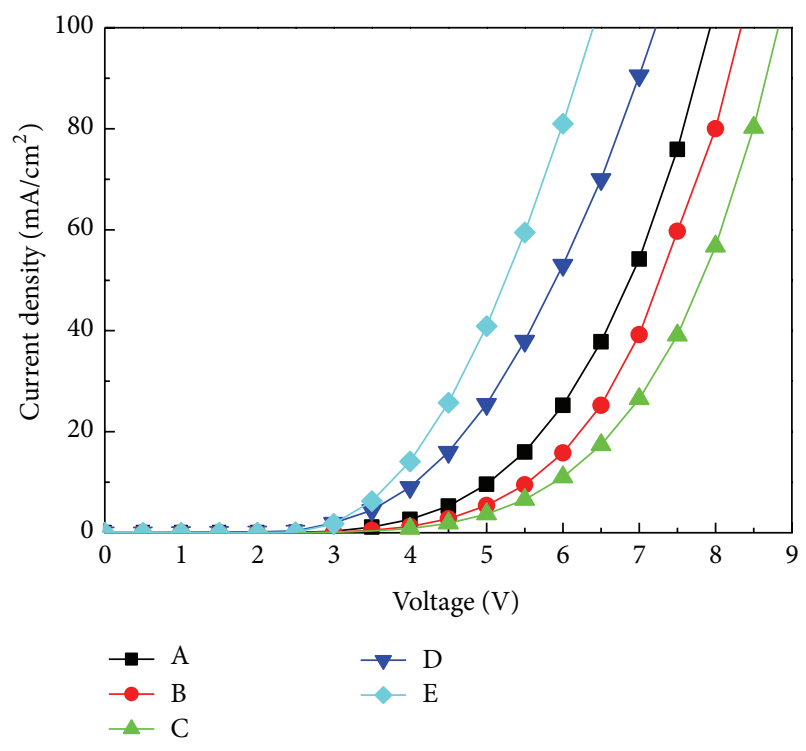

(a)

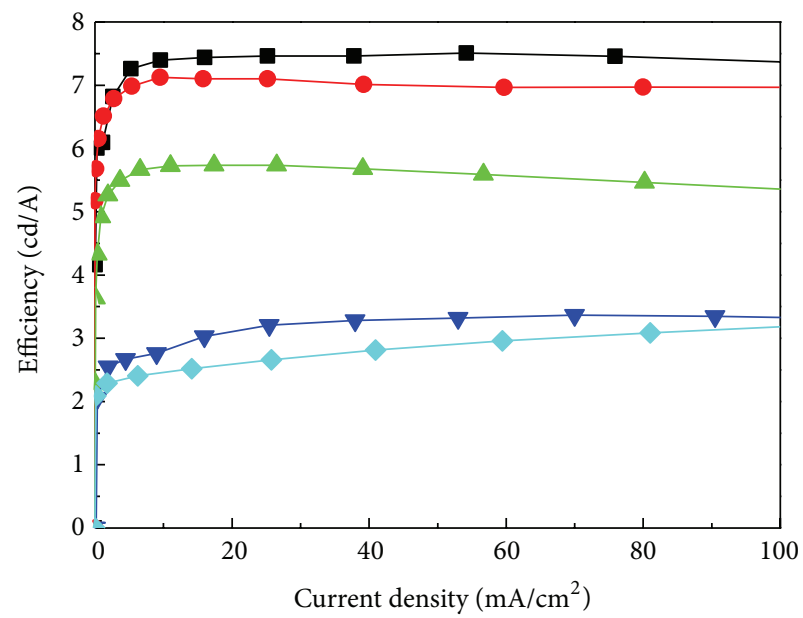

(b)

FIGURE 1: (a) Luminance versus bias voltage and (b) electroluminescence efficiency versus current density of devices A to E.

the EL efficiency degradation was most likely due to the decrease in the created exciton density and radiative efficiency. When the deposition rate for the last $5 \mathrm{~nm} \mathrm{Bebq} 2$ layer was decreased from 1.3 to $0.03 \mathrm{~nm} / \mathrm{s}$, the device exhibited a significantly longer lifetime compared to similar devices with no change in the deposition rate. The extracted half lifetimes of the OLEDs with a two-step deposition process (devices A and B) were 1200 and $833 \mathrm{~min}$. at deposition rates of 0.03 and 0.3 , respectively, for ultrathin $\mathrm{Bebq}_{2}(5 \mathrm{~nm})$ on the bulk material $(55 \mathrm{~nm})$. This suggested that modifying the organic/electrode interface at the electron contact of OLED can significantly improve their operational reliability. In contrast, the corresponding half lifetimes of bulk $\mathrm{Bebq}_{2}$ devices with constant deposition rate were 410,288 , and $214 \mathrm{~min}$. at deposition rates of $1.3,0.3$, and $0.03 \mathrm{~nm} / \mathrm{s}$, respectively. The extracted device lifetimes (devices C, D, and E) 


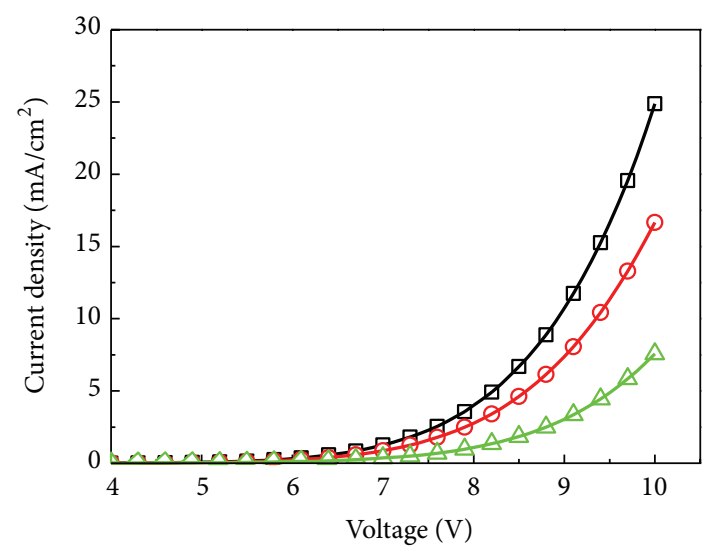

FIGURE 2: Current density versus bias voltage characteristics of electron-only devices with a $\mathrm{Bebq}_{2}$ layer deposited at three deposition rates (solid line, $0.03 \mathrm{~nm} / \mathrm{s}$; dashed line, $0.3 \mathrm{~nm} / \mathrm{s}$; dotted line, $1.3 \mathrm{~nm} / \mathrm{s})$.

decreased as the film deposition rate decreased. The PL intensities were measured before and after the aging process, with decreases of $3.6 \%, 4 \%, 4.3 \%, 20 \%$, and $35 \%$ observed for devices $A, B, C, D$, and $E$, respectively. One should note that the PL decrease was the most pronounced for device E. On the contrary, as shown in Figure 3(b), the voltage increase was highest for the OLED with the highest deposition rate (device C). By using a low deposition rate $\mathrm{Bebq}_{2}$ at the $\mathrm{LiF} / \mathrm{Al}$ interface, the voltage increase was significantly alleviated in devices A and B. The voltage increase in an aged OLED is due to the trap density formation [21-23]. By comparing devices $\mathrm{C}, \mathrm{D}$, and $\mathrm{E}$, one may conclude that the lower deposition rates helped to reduce the trap formation. Device A exhibited the lowest voltage increase rate (even lower than device E), however, indicating that the trap distribution upon electrical aging was different under different deposition rates. For device $\mathrm{C}$, with the highest deposition rate $\mathrm{Bebq}_{2}$, traps were formed near the interface in direct contact with the cathode. On the other hand, for device E, the traps were mainly located away from the cathode side. With the two-step evaporation process, the trap formation rate for the entire $\mathrm{Bebq}_{2}$ layer was decreased, extending the operating lifetime. This explained the differences in the EL lifetimes among devices A, B, and C, despite similar PL decay rates.

3.3. Surface Morphology. To further investigate the possible physical mechanisms in play, we examined the correlation of the morphology of the $\mathrm{Bebq}_{2}$ layer with other devices prepared on $\mathrm{Si}$ wafer [4]. Although the situation of $\mathrm{Bebq}_{2}$ deposited on Si substrate may be different from that on ITO glass, unfortunately, the surface of ITO is quite rough making it unsuitable for studying the surface condition of $\mathrm{Bebq}_{2}$ thin film. Figure 4 shows the AFM surface morphology measurement of the bulk $\mathrm{Bebq}_{2}$ films from the twostep deposition process. Such layers were fabricated with a constant deposition rate of $1.3 \mathrm{~nm} / \mathrm{s}(55 \mathrm{~nm})$ for the bulk material, followed by deposition of the last $5 \mathrm{~nm}$ ultrathin layer at the three different deposition rates of $0.3,0.03$, and

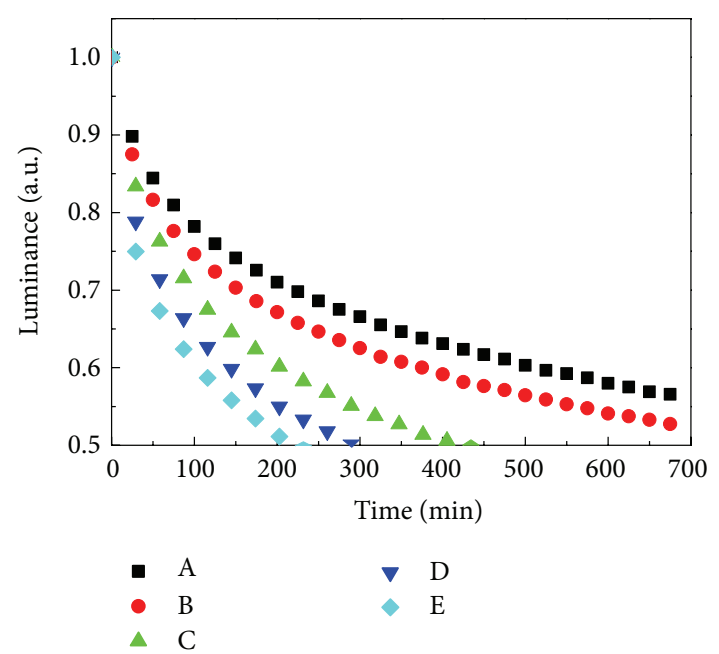

(a)

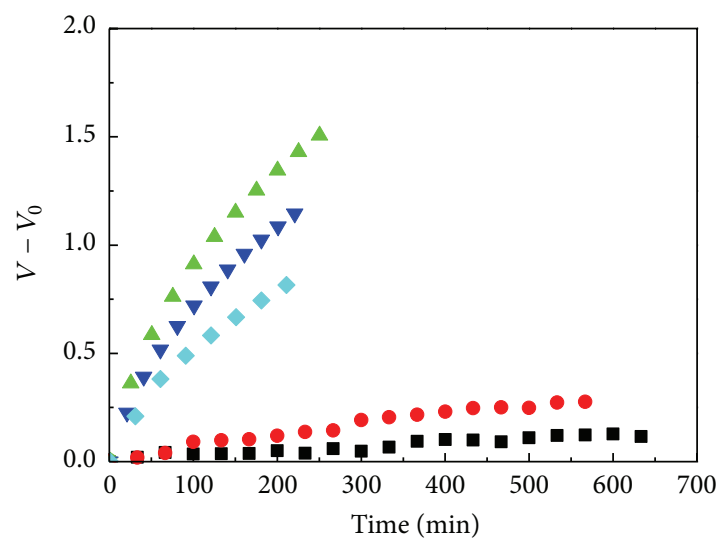

(b)

FIGURE 3: (a) Normalized luminance $\left(L^{*}\right)$ and (b) voltage variation $\left(V-V_{0}\right)$ versus operating time of five types of OLED structure. The last $5 \mathrm{~nm} \mathrm{Bebq}$ layer prepared with a two-step process (device A, $0.03 \mathrm{~nm} / \mathrm{s}$ and device $\mathrm{B}, 0.3 \mathrm{~nm} / \mathrm{s})$ on bulk Bebq ${ }_{2}(55 \mathrm{~nm}$ and $1.3 \mathrm{~nm} / \mathrm{s}$ ). The reference devices were used at the constant deposition rates of 1.3 (device C), 0.3 (device D), and 0.03 (device E) nm/s in bulk $\mathrm{Bebq}_{2}$ EML/ETL $(60 \mathrm{~nm})$. All devices were driven with constant current density of $100 \mathrm{~mA} / \mathrm{cm}^{2}$.

$1.3 \mathrm{~nm} / \mathrm{s}$ upon the bulk $\mathrm{Bebq}_{2}$. The scanning area of these images was $2 \times 2 \mu \mathrm{m}$ and the morphology of all films revealed a similar island-like surface texture. The average root-meansquare (RMS) roughness of the ultrathin $\mathrm{Bebq}_{2}$ films with deposition rates of $0.03,0.3$, and $1.3 \mathrm{~nm} / \mathrm{s}$ on bulk $\mathrm{Bebq}_{2}$ surface was about $0.26,0.30$, and $0.38 \mathrm{~nm}$, respectively (see Figures 4(a), 4(b), and 4(c)). We also extracted the variation values (the extracted values correspond to the highest and lowest heights) of these devices: $0.95,1.35$, and $1.55 \mathrm{~nm}$ for the ultrathin layer deposited at $0.03,0.3$, and $1.3 \mathrm{~nm} / \mathrm{s}$, respectively (see Figures $4(\mathrm{~d}), 4(\mathrm{e})$, and $4(\mathrm{f})$ ). Note that in Figure 4 (c) the deposition rate was kept at $1.3 \mathrm{~nm} / \mathrm{s}$ for the whole $60 \mathrm{~nm}$. The surface is rough and there are numerous "white spots" with a diameter $\sim 200 \mathrm{~nm}$. When decreasing the deposition rate for the final $5 \mathrm{~nm}$ at 0.3 and $0.03 \mathrm{~nm} / \mathrm{s}$, 


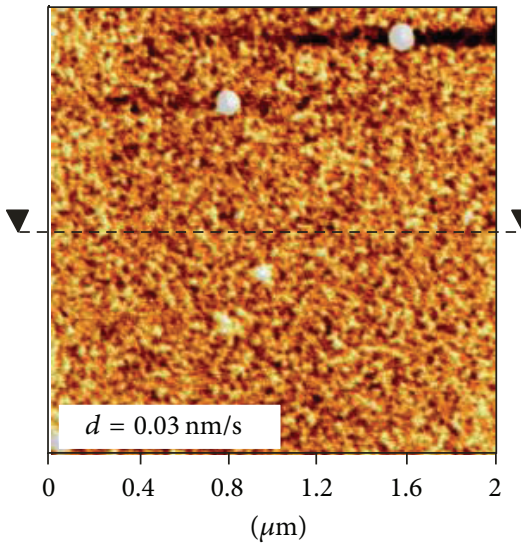

(a)

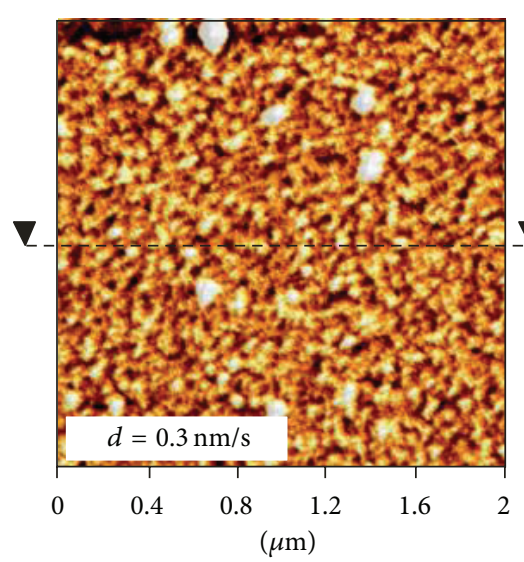

(b)

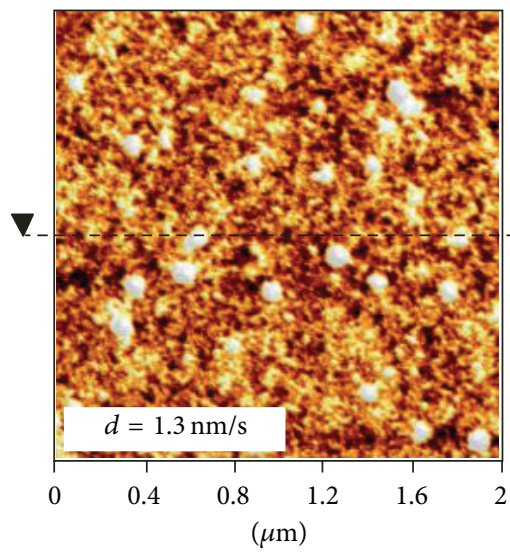

(c)

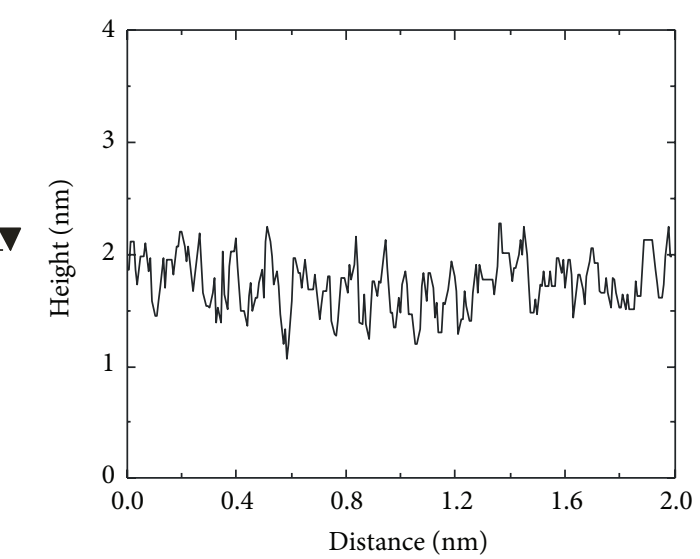

(d)

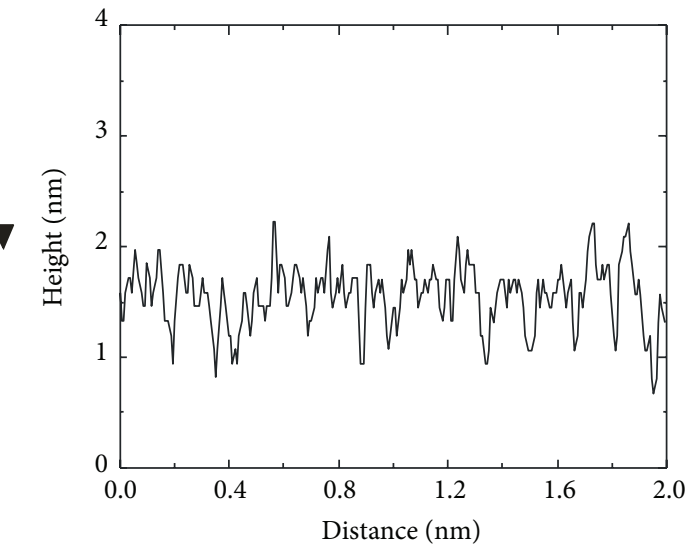

(e)

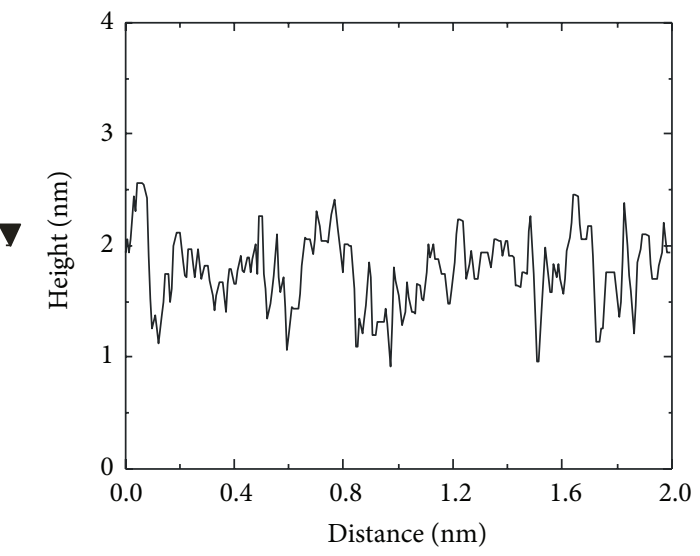

(f)

FIGURE 4: The atomic force microscope micrographs of $\mathrm{Bebq}_{2}(5 \mathrm{~nm})$ films prepared with different deposition rates of (a) 0.03 , (b) 0.3 , and (c) $1.3 \mathrm{~nm} / \mathrm{s}$ on the bulk material of $\mathrm{Bebq}_{2}(55 \mathrm{~nm} ; 1.3 \mathrm{~nm} / \mathrm{s})$ substrate. The depth profiles of ultrathin $\mathrm{Bebq}_{2}$ with three deposition rates of 0.03 (d), 0.3 (e), and 1.3 (f) $\mathrm{nm} / \mathrm{s}$ were extracted from the centerline of corresponding images.

it can be seen that the surface became smooth and the number of "white spots" decreased. The dependence of the morphology results on the deposition rate can be explained by the fact that a lower deposition rate in the ultrathin layer enabled the planar $\mathrm{Bebq}_{2}$ molecules to settle into their lowest energy-packing configuration and produce a smooth surface (see Figure $4(\mathrm{~d})$ ). The optimization of the two-step process resulted in a significant decrease to the RMS roughness of the
$\mathrm{Bebq}_{2}$ surface and the formation of a "good contact" interface between $\mathrm{Bebq}_{2} /$ electrode. Consequently, we expect that such smooth contact would eliminate the obstruction buildup at the interface between organic/electrode. Conversely, the rough surface morphology of $\mathrm{Bebq}_{2}$ film (see Figures 4(e) and $4(f)$ ) may result in weak adhesion of the subsequently deposited electrode layer and decrease the electron injection efficiency. The present results suggest that these factors are 
strongly affected by the interface qualities of $\mathrm{Bebq}_{2} /$ electrode under different deposition rates. With the modification of the contact layer, the $5 \mathrm{~nm} \mathrm{Bebq}$, with lower deposition rate produced a uniform buffer layer that reduced the driving voltage and gave a higher efficiency due to better charge balance. At a low deposition rate, the smooth $\mathrm{Bebq}_{2} /$ electrode interface also facilitated stable contact for the subsequently deposited LiF/Al electrode. This explained why the trap distribution upon electrical aging was predominantly concentrated on the cathode side with high deposition rate $\mathrm{Bebq}_{2}$ (device C). On the other hand, for device $\mathrm{E}$ with low deposition rate $\mathrm{Bebq}_{2}$, the efficiency was low (as shown in Figure 1(b)), resulting in more serious joule heating near the recombination zone (HTL/Bebq 2 interface) that assisted the crystallization process $[24,25]$ and decreased the PL efficiency.

\section{Conclusion}

We investigated the influence of the deposition rate of the $\mathrm{Bebq}_{2}$ film on the performance of OLEDs with a $\mathrm{Bebq}_{2}$ film and reached two conclusions. First, the current densities versus driving voltage and luminance versus current densities characteristics of the devices were found to be consistent with the extracted dependence of the carrier injection properties on the film deposition rate. In particular, when ultrathin films were fabricated at low deposition rates, the formation of a smooth $\mathrm{Bebq}_{2}$ surface may strongly enhance charge injection. This conclusion was supported by the electron-only measurements. Second, when the deposition rate for the last $5 \mathrm{~nm} \mathrm{Bebq} \mathrm{q}_{2}$ layer was decreased from 1.3 to $0.03 \mathrm{~nm} / \mathrm{s}$, the devices exhibited significantly longer lifetimes compared to similar devices with no changes in the deposition rate. This indicated that the two-step deposition process was responsible for a significant increase in the surface smoothness of the $\mathrm{Bebq}_{2} /$ electrode interface, possibly due to the strong and stable adhesion of $\mathrm{Bebq}_{2}$ and subsequently deposited $\mathrm{Al}$ electrode.

\section{Conflict of Interests}

The authors declare that they have no conflict of interests regarding the publication of this paper.

\section{Acknowledgments}

The authors thank the financial support by the National Science Council, ROC, under Grant nos. NSC 101-2221E-002-156-MY3, 102-2221-E-002-182-MY3, NSC 102-2221-E131-026-MY2, NSC 102-2221-E-131-030-MY2, NSC 102-2511S-131-002, NSC 103-ET-E-011-004-ET, NSC 102-2627-E-002002, and NSC 102-2622-E-011-018-CC3 and Academia Sinica of Taiwan.

\section{References}

[1] H. Klauk, "Organic thin-film transistors," Chemical Society Reviews, vol. 39, pp. 2643-2666, 2010.
[2] G. Li, R. Zhu, and Y. Yang, "Polymer solar cells," Nature Photonics, vol. 6, no. 3, pp. 153-161, 2012.

[3] B. J. Chen, W. Y. Lai, Z. Q. Gao, C. S. Lee, S. T. Lee, and W. A. Gamblig, "Electron drift mobility and electroluminescent efficiency of tris(8-hydroxyquinolinolato) aluminum," Applied Physics Letters, vol. 75, p. 4010, 1999.

[4] C. B. Lee, A. Uddin, X. Hu, and T. G. Andersson, "Study of $\mathrm{Alq}_{3}$ thermal evaporation rate effects on the OLED," Materials Science and Engineering: B, vol. 112, pp. 14-18, 2004.

[5] T. Matsushima, K. Shiomura, S. Naka, and H. Murata, "Optical, morphological, structural, electrical, molecular orientation, and electroluminescence characteristics of organic semiconductor films prepared at various deposition rates," Thin Solid Films, vol. 520, no. 6, pp. 2283-2288, 2012.

[6] H. W. Zan, Y. H. Hsu, H. F. Meng, C. H. Huang, Y. T. Tao, and W. W. Tsai, "High output current in vertical polymer spacecharge-limited transistor induced by self-assembled monolayer," Applied Physics Letters, vol. 101, no. 9, Article ID 093307, 2012.

[7] S. Pola, C. H. Kuo, W. T. Peng, M. M. Islam, I. Chao, and Y. T. Tao, "Contorted tetrabenzocoronene derivatives for single crystal field effect transistors: correlation between packing and mobility," Chemistry of Materials, vol. 24, pp. 2566-2571, 2012.

[8] F. Padinger, R. S. Rittberger, and N. S. Sariciftci, "Effects of postproduction treatment on plastic solar cells," Advanced Functional Materials, vol. 13, no. 1, pp. 85-88, 2003.

[9] G. Li, V. Shrotriya, J. Huang et al., "High-efficiency solution processable polymer photovoltaic cells by self-organization of polymer blends," Nature Materials, vol. 4, no. 11, pp. 864-868, 2005.

[10] H. C. Han, C. A. Tseng, C. Y. Du et al., "Enhancing efficiency with fluorinated interlayers in small molecule organic solar cells," Journal of Materials Chemistry, vol. 22, pp. 22899-22905, 2012.

[11] C.-F. Lin, S.-W. Liu, C.-C. Lee et al., "Open-circuit voltage and efficiency improvement of subphthalocyanine-based organic photovoltaic device through deposition rate control," Solar Energy Materials and Solar Cells, vol. 103, pp. 69-75, 2012.

[12] C. C. Lee, S. W. Liu, and Y. T. Chung, "Effect of deposition rate on device performance and lifetime of planar molecule-based organic light-emitting diodes," Journal of Physics D: Applied Physics, vol. 43, no. 7, Article ID 075102, 2010.

[13] J.-H. Lee, C.-I. Wu, S.-W. Liu, C.-A. Huang, and Y. Chang, "Mixed host organic light-emitting devices with low driving voltage and long lifetime," Applied Physics Letters, vol. 86, Article ID 103506, 2005.

[14] S.-W. Liu, C.-C. Lee, C.-H. Wang, J.-H. Lee, C.-T. Chen, and J.-K. Wang, "Enhancing performance of planar moleculebased organic light-emitting diodes through deposition-rate optimization: role of molecular packing," Chemical Physics Letters, vol. 474, pp. 207-211, 2009.

[15] S.-H. Liao, J.-R. Shiu, S.-W. Liu et al., "Hydroxynaphthyridinederived group III metal chelates: wide band gap and deep blue analogues of green $\mathrm{Alq}_{3}$ (tris(8-hydroxyquinolate)aluminum) and their versatile applications for organic light-emitting diodes," Journal of the American Chemical Society, vol. 131, pp. 763-777, 2009.

[16] W. Brütting, S. Berleb, and A. G. Mückl, "Device physics of organic light-emitting diodes based on molecular materials," Organic Electronics, vol. 2, pp. 1-36, 2001. 
[17] S. T. Lee, Z. Q. Gao, and L. S. Hung, "Metal diffusion from electrodes in organic light-emitting diodes," Applied Physics Letters, vol. 75, p. 1404, 1999.

[18] J.-H. Lee, Y.-H. Ho, T.-C. Lin, and C.-F. Wu, "High-efficiency fluorescent blue organic light-emitting device with balanced carrier transport," Journal of the Electrochemical Society, vol. 154, pp. 226-228, 2007.

[19] H. Aziz, Z. D. Popovic, and N.-X. Hu, "Organic light emitting devices with enhanced operational stability at elevated temperatures," Applied Physics Letters, vol. 81, p. 370, 2002.

[20] C.-C. Lee, M.-Y. Chang, P.-T. Huang, Y.-C. Chen, and S.-W. Liu, "Electrical and optical simulation of organic light-emitting devices with fluorescent dopant in the emitting layer," Journal of Applied Physics, vol. 101, p. 114501, 2007.

[21] S. A. Van Slyke, C. H. Chen, and C. W. Tang, "Organic electroluminescent devices with improved stability," Applied Physics Letters, vol. 69, no. 15, pp. 2160-2162, 1996.

[22] D. Y. Kondakov, J. R. Sandifer, C. W. Tang, and R. H. Young, "Nonradiative recombination centers and electrical aging of organic light-emitting diodes: direct connection between accumulation of trapped charge and luminance loss," Journal of Applied Physics, vol. 93, no. 2, pp. 1108-1119, 2003.

[23] J.-H. Lee, J.-J. Huang, C.-C. Liao, P.-J. Hu, and Y. Chang, "Operation lifetimes of organic light-emitting devices with different layer structures," Chemical Physics Letters, vol. 402, pp. 335-339, 2005.

[24] J. R. Gong, L. J. Wan, S. B. Lei, C. L. Bai, X. H. Zhang, and S. T. Lee, "Direct evidence of molecular aggregation and degradation mechanism of organic light-emitting diodes under joule heating: an STM and Photoluminescence study," The Journal of Physical Chemistry B, vol. 109, pp. 1675-1682, 2005.

[25] H. Aziz and Z. D. Popovic, "Degradation phenomena in small-molecule organic light-emitting devices," Chemistry of Materials, vol. 16, pp. 4522-4532, 2004. 

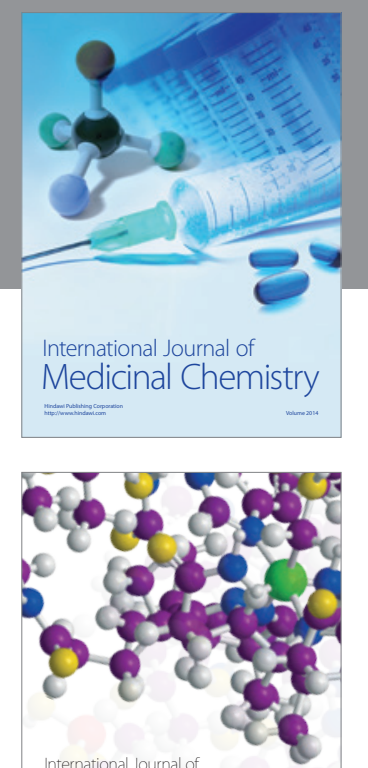

\section{Carbohydrate} Chemistry

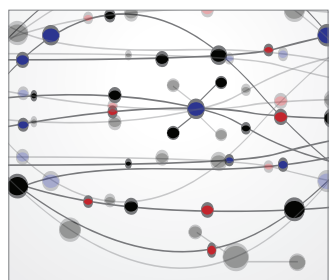

The Scientific World Journal
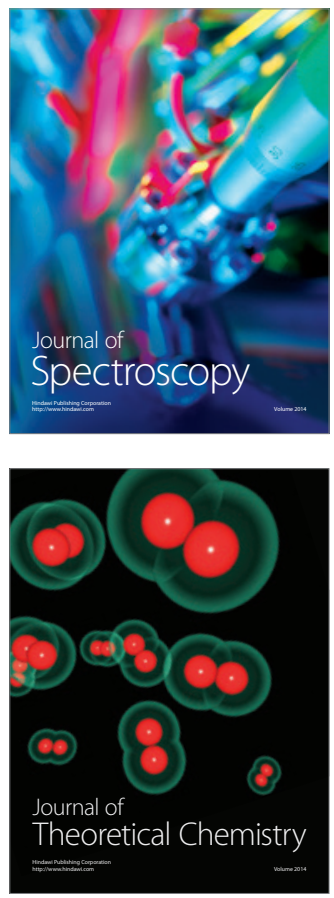
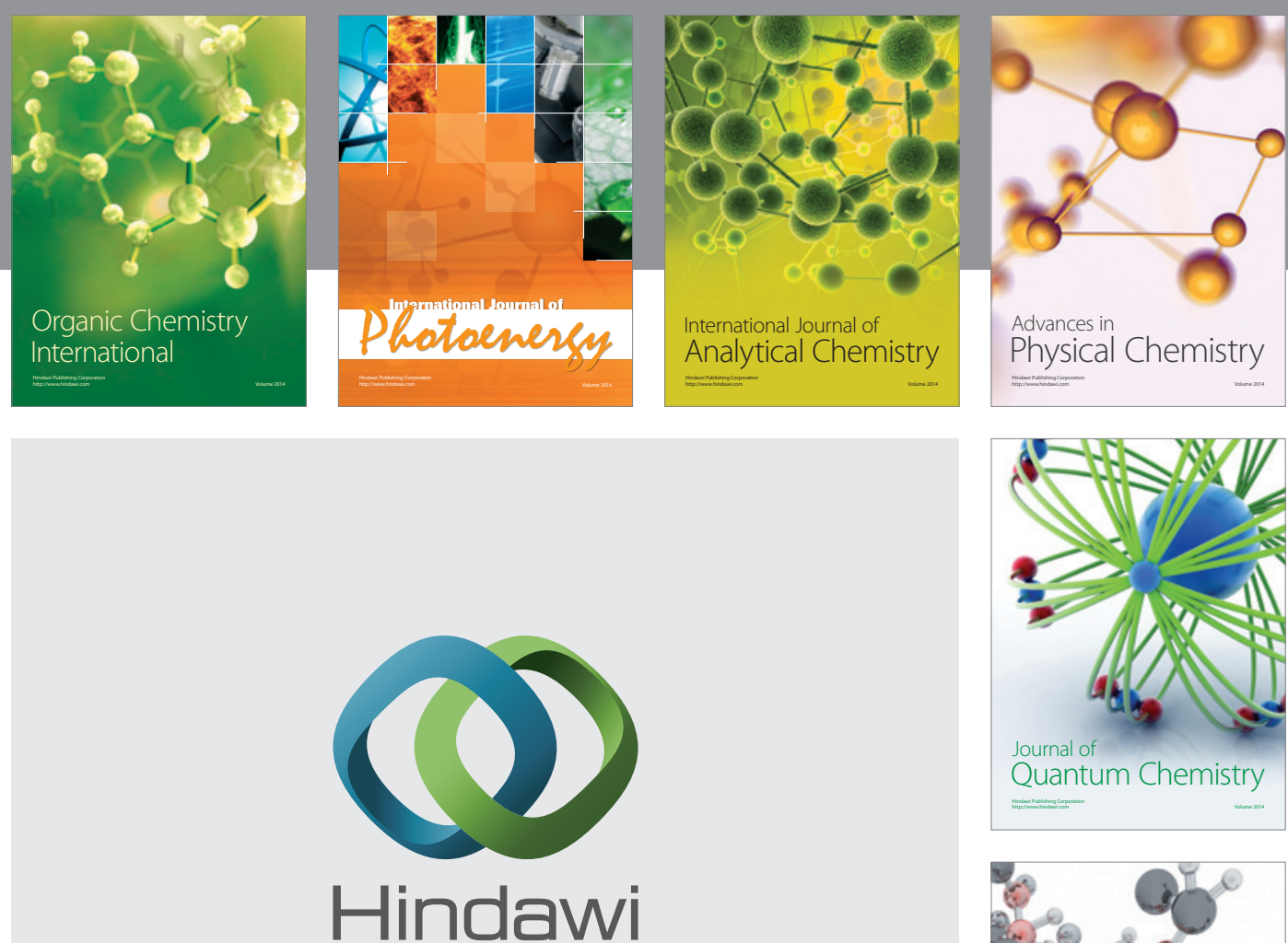

Submit your manuscripts at

http://www.hindawi.com

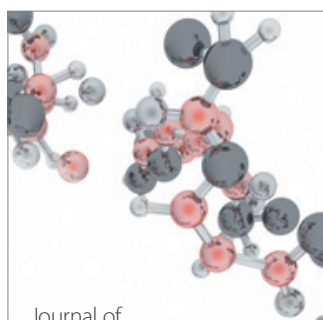

Analytical Methods

in Chemistry

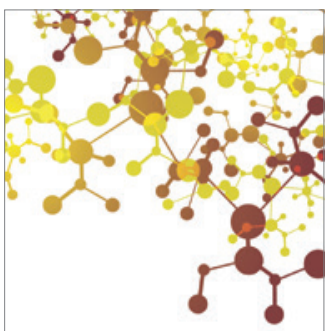

Journal of

Applied Chemistry

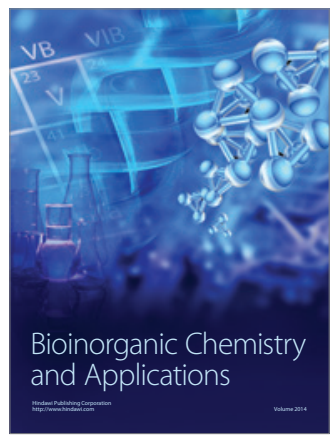

Inorganic Chemistry
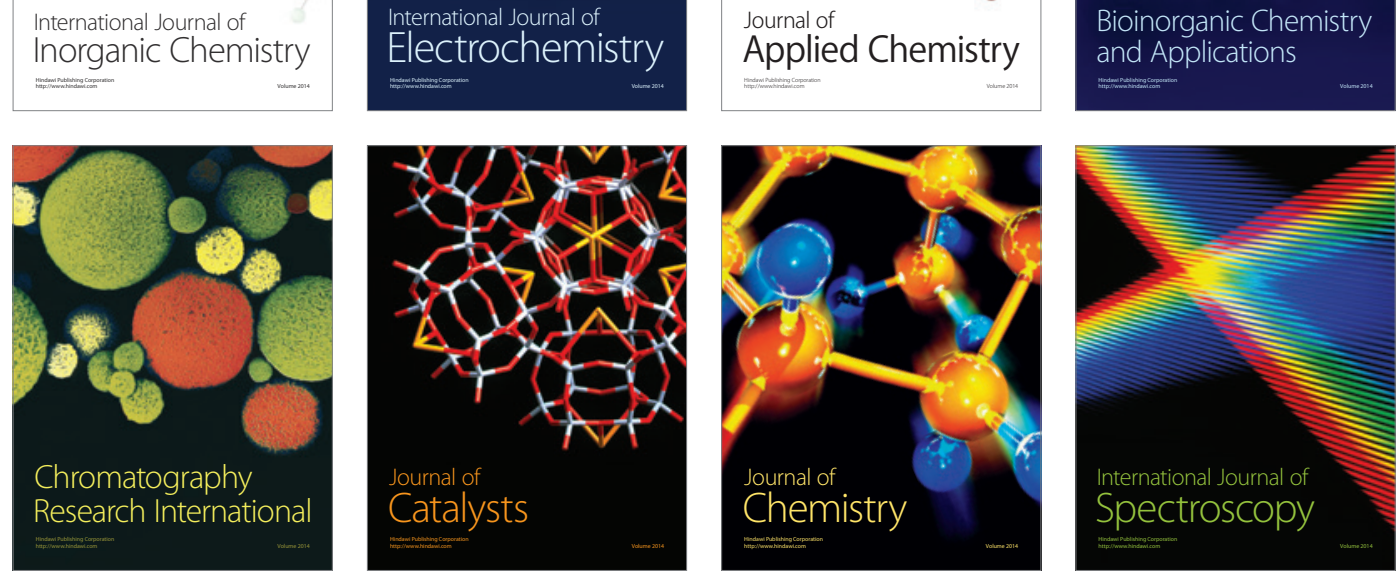